\title{
SYSTEMA V DE INSTITUTIONE MUSICA - PROPOJENÍ ARITMETIKY, GEOMETRIE A HUDBY
}

Boëthiův spis De institutione musica ${ }^{1}$ představuje v latinském hudebním písemnictví nezpochybnitelnou autoritu, na kterou se odvolává řada pozdějších autorů. Z hlediska metodologických prístupů $\mathrm{k}$ fenoménu musica můžeme považovat Boëthia za představitele pythagorejské tradice a jak je zjevné z pozdějších pramenů, tato tradice výrazně předurčila vývoj uvažování o hudbě během středověku. Nahlíženo současnou perspektivou, mluvíme o spekulativní tradici, $\mathrm{v}$ rámci které je fenomén musica včleněn do disciplín quadrivia, charakteristických svou vzájemnou analogičností.

V předkládané studii se budeme zabývat konstrukcí řeckého tónového systému - systema teleion, včetně metody jeho odvození2. Právě metoda, kterou Boëthius používá pro odvození diatonických, chromatických a enharmonických tetrachordů, je charakteristická pro pythagorejskou tradici zdůrazňující aritmetickou podstatu hudby ${ }^{3}$. A ačkoli je toto paradigma $\mathrm{z}$ hlediska novověku krajně spekulativ-

1 GODOFREDUS Friedlein (ed.). Anicii Manlii Torquati Severini Boetii De institutione arithmetica libri duo: De institutione musica libri quinque. Accedit geometria quae fertur Boetiis. Lipsko: B.G.Teubner, 1867; dále viz kritická edice BoEthius, Anicius Manlius Severinus. Fundamentals of Music. Přel. Calvin M. Bower, ed. Claude V. Palisca. New Haven \& London: Yale University Press, 1989.

GODOFREDUS Friedlein (ed.). Anicii Manlii Torquati Severini Boetii..., op. cit., kniha čtvrtá, s. 314-334.

Boëthius odvozuje aritmeticky diatonické, chromatické a enharmonické tetrachordy v kapitolách: VI. Monochordi netarum hyperboleon per tria genera partitio, ibid., s. 318-322, VIII. Monochordi netarum diezeugmenon per tria genera partitio, ibid., s. 324-327, VIIII. Monochordi netarum synemmenon per tria genera partitio, , ibid., s. 327-330, X. Monochordi meson per tria genera partitio, ibid., s. 330-332, XI. Monochordi hypaton per tria genera partitio et totius dispositio descriptionis, ibid., s. 332-334. Je tedy zde odvozeno všech pět tetrachordů řeckého tónového systému. Názvy tetrachordů se rrídí horním stupněm, od kterého je tetrachord odvozen: nété hypebolaión, nété diezeugmenón, nété synémmenón, mesé a hypaté mesón. Pozn. v textu této studie jsou použity psané tvary řeckých stupňů v podobě, v jaké je uvádí Černý, viz ČERnÝ, Miroslav K. Hudba antických kultur. Praha: Academia, 2006, s. 23 a dále. 
ní, pokud se podíváme na genezi vztahu hudby, aritmetiky a geometrie, musíme uznat, že tyto spekulace nejsou prosty empirie. Na tento fakt ostatně poukazuje sám Boëthius již v první knize De istitutione musica, kde v desáté kapitole Quemadmodum Pythagoras proportiones consonantiarum investigaverit ${ }^{4}$ popisuje „objev“ vztahů mezi aritmetikou a hudbou. Ačkoli můžeme o této epizodě ze života Pythagory pochybovat z hlediska historického faktu (je tedy spíše fabulací a mýtem), její podání nám odkrývá způsob uvažování o problému. Ostatně i v rámci kapitoly, ve které Boëthius geometricky dělí monochord, je empirické hledisko vztahu hudby, č́sla a geometrie evidentní:

„De qua re illud est praedicendum, quod, sive in mensura nervi, sive in numeris atque eorum proportione statuatur describenda divisio, maius spatium chordae et maior numeri multitudo sonos graviores efficiet. At si fuerit nervi longitudo contractior et in numeris non multa pluralitas, acutiores voces edi necesse est. " 5

„,Vzhledem $k$ této věci musi být nejdřive řečeno, že jak v děleni struny, tak i čísel a jejich proporcí za předpokladu jejich dělení, větši délka struny a větš̌i číselná hodnota způsobuje hlubši zvuk. Ale pokud je délka struny zmenšena a čiselná hodnota neni početná, zvuky jsou nutně vyšši "

Souvislost geometrických a aritmetických analogií vzhledem ke smyslové zkušenosti je tedy zřejmá. Boëthius odvozuje řecký tónový systém dvěma odlišnými metodami: geometrickým dělením a aritmetickou argumentací. Geometrická metoda je použita pro ustavení řeckého systema teleion jako celku v rovině diatonického rodu. Aritmetické metody je použito k odvození všech tř́ rodů (diatonického, chromatického a enharmonického) v rovině jednotlivých tetrachordů. Nejdříve se podíváme na rekonstrukci dělení geometrického, které Boëthius představuje v kapitole Monochordi regularis partitio in genere diatonico ${ }^{6}$. Pro přehlednou rekonstrukci je možné celé dělení rozvrhnout $\mathrm{v}$ parafrázi Boëthia do následujících devíti kroků:

1. Úsečka $A B^{7}$ představuje celek - strunu, monochord.

2. Rozdělme úsečku $\mathrm{AB}$ na čtyři díly, dostaneme tak tři body: $\mathrm{C}, \mathrm{D}$ a $\mathrm{E}$. $\mathrm{AB}$ je tak dvojnásobek $\mathrm{DB}$ a $\mathrm{AD}$ (tedy proporce 2:1), úsečky $\mathrm{AD}$ a $\mathrm{DB}$ jsou každá dvojnásobek $\mathrm{AC}, \mathrm{CD}, \mathrm{DE}$ a $\mathrm{EB}$. Úsečka $\mathrm{AB}$ představuje stupeň proslambanomenos

$4 \quad$ Ibid., s. 196-198.

5 Ibid., s. 314-316, kniha čtvrtá, kapitola pátá Monochordi regularis partitio in genere diatonico.

6 Ibid., s. 314-316.

7 „Chorda intensa“, což lze přeložit jako „natažená struna“, př́ípadně „napnutá struna“. Opět poukaz na praktickou aplikabilitu takového dělení. Nejedná se tedy o izolovanou geometrickou reprezentaci, nýbrž o skutečné, praktické dělení monochordu. Ibid., s. 315. 
(nejnižší stupeň systema teleion), DB mesé (střed systema teleion, o oktávu 2:1 výš, než proslambanomenos), EB nété hypebolaión (nejvyšší stupeň systema teleion, o oktávu 2:1 výš než mesé a o dvě oktávy 4:1 výšs, než proslambanomenos). Jelikož $\mathrm{AB}$ obsahuje čtyři díly a $\mathrm{CB}$ tři, jsou tyto úsečky v proporčním vztahu 4:3 a CB tak představuje stupeň lichanos hypatón diatonon (o kvartu výš než proslambanomenos).

3. Odečteme jednu devítinu z $A B$ a dostaneme bod F, resp. úsečku FB. Vztah AB ku FB tak představuje proporci 9:8, tedy interval celý tón. Úsečka FB představuje stupeň hypaté hypatón.

4. Rozdělme úsečku AB na tři části. AG je jedna část, GB jsou dvě. Tj. AB:GB je proporce 3:2 (interval kvinty), GB představuje stupeň hypaté mesón.

5. Odečteme jednu čtvrtinu z CB a dostaneme KB. CB:KB je proporce $4: 3$, tedy kvarta (diatessaron). KB představuje stupeň lichanos mesón diatonon.

6. Odečteme jednu devítinu od DB a dostaneme LB, úsečka LB představuje stupeň paramesé.

7. Odečteme jednu čtvrtinu od $\mathrm{DB}$ a dostaneme $\mathrm{MB}$, úsečka $\mathrm{MB}$ představuje stupeň nété synémmenón.

8. Odečteme jednu třetinu od $\mathrm{DB}$ a dostaneme NB, úsečka NB představuje stupeň nété diezeugmenón.

9. Rozdělme úsečku KB na dvě stejné části bodem X, dostaneme KX a XB. Úsečka XB představuje stupeň paranété hypebolaión.

Výsledek tohoto geometrického dělení si můžeme shrnout do následujícího prehledu stupňů od nejnižšího po nejvyšší (včetně značení jednotlivých úseček dělení):
$\mathrm{AB}=$ proslambanomenos
$\mathrm{FB}=$ hypaté hypatón
$\mathrm{CB}=$ lichanos hypatón diatonon
$\mathrm{GB}=$ hypaté mesón
$\mathrm{KB}=$ lichanos mesón diatonon
$\mathrm{DB}=$ mesé
$\mathrm{LB}=$ paramesé
$\mathrm{MB}=$ nété synémmenón
$\mathrm{NB}=$ nété diezeugmenón
$\mathrm{XB}=$ paranété hypebolaión diatonon
$\mathrm{EB}=$ nété hypebolaión 
Vidíme, že některé stupně diatonického rodu chybí, jmenovitě (stupeň paranété diezeugmenón diatonon se $\mathrm{v}$ př́padě Boëthiova dělení nijak proporčně neliší od nété synémmenón, proto jej neuvádíme):

(i) z tetrachordu hypatón:

parhypaté hypatón diatonon

(ii) z tetrachordu mesón:

parhypaté mesón diatonon

(iii) z tetrachordu synémmenón:

trité synémmenón diatonon

paranété synémmenón diatonon (zde se opět jedná o proporční shodu s následujícím chybějícím stupněm trité diezeugmenón diatonon)

(iv) z tetrachordu diezeugmenón:

trité diezeugmenón

(v) z tetrachordu hypebolaión:

trité hypebolaión

Podle všeho došlo v tradování latinského textu (resp. verzí a opisů) ke ztrátě pasáže, ve které se odvozují právě tyto diatonické půltóny. ${ }^{8}$ Je totiž krajně nepravděpodobné, že by Boëthius geometricky odvozoval záměrně pouze celotónové stupně, jelikož takovým stupněm je i chybějící paranété synémmenón diatonon. Po této částečné geometrické konstrukci diatonického rodu přistupuje Boëthius $\mathrm{k}$ velice důslednému aritmetickému dělení jednotlivých tetrachordů ve všech třech rodech. Jako první odvozuje v řeckém tónovém systému nejvýše situovaný tetrachord hypebolaión. Ačkoli Boëthius zde použivá aritmetické odvození jednotlivých stupňů, $v$ protikladu k čistě geometrickému dělení ${ }^{9}$, koncept

8 Tento problém řešili také editoři kritické edice De institutione musica, ve které bylo přistoupeno na pokus o rekonstrukci textu. Viz Boethius, Anicius Manlius Severinus. Fundamentals of Music, op. cit., s. 130.

9 Dělení monochordu v předchozí kapitole Monochordi regularis partitio in genere diatonico je čistě geometrické, bez aritmetické argumentace. Dělení touto metodou lze chápat jako empiricky uchopitelnou demonstraci řeckého systema teleion. Proto lze považovat Boethiovo Monochordi regularis partitio za pokračování eukleidovské tradice. Viz CelHoffer, Martin. „Sectio canonis. Geometrická konstrukce hudebních intervalů řeckého systema teleion“, Opus musicum, 2012, roč. 44, č. 2, s. 59-67; viz dále: Mathiesen, Thomas J. An Annotated Translation of Euclid“s „Division of a Monochord“. Journal of Music Theory, 1975, roč. 19, č. 2, s. 249-252. V souvislosti s navazující středověkou tradicí těchto geometrických dělení viz pojednání Epistola de ignoto cantu directa Guida z Arezza, in Scriptores ecclesiastici de musica sacra potissimum, 3 sv., Martin Gerbert (ed.), St. Blaise: Typis San-Blasianis, 1784, 2:43-50; a rovněž i Micrologus, in Ibid., 2:2-24. Dále také vlivný spis Musica Johannese de Cotto (Ex MS. San-Blas. saec. XII. collato cum Vindobonensi \& Lipsiensi, in: Scriptores 
monochordu jako struny zůstává i zde zachován. Možným důvodem použití aritmetické argumentace je existence specifických intervalů $v$ řecké chromatice a zejména enharmonice. Nicméně i takové dělení je prakticky aplikovatelné na struně monochordu a nebude tak výlučně matematickou spekulací.

Před samotným aritmetickým dělením tetrachordu hypebolaión např́íc všemi rody je pro Boëthia nutností aritmeticky definovat nejvyšší stupeň řeckého systema - nété hypebolaión, od kterého jsou zbylé stupně tetrachordu hypebolaión odvozeny. Je to přirozené, protože odvozování jednotlivých stupňủ tetrachordu musí probíhat sestupně kvůli půltónu, př́ípadně diesis na nejnižším stupni. Tento fakt by představoval problém vzhledem k poměrně složitým proporcím intervalů menších jako celý tón a jejich př́ípadnému nanášení na monochord. Podobně je nutné definovat předem i stupně proslambanomenos a mesé. Je zajímavé, že ačkoli Boëthius má již geometricky odvozeny všechny nepohyblivé stupně řeckého systema ${ }^{10}$, nerespektuje ustavené alfabetické označení jednotlivých stupňů na monochordu (co také odkazuje na naprosto odlišnou metodu odvozování): ${ }^{11}$
$\mathrm{A}=$ proslambanomenos
9216
$\mathrm{O}=$ mesé 4608
$\mathrm{LL}=$ nété hypebolaión
2304

Vidíme, že z hlediska proporčnosti platí 2. teze předchozího dělení: oktáva 2:1 mezi proslambanomenos a mesé a mezi mesé a nété hypebolaión; dvě oktávy 4:1 mezi proslambanomenos a nété hypebolaión. Další stupně tetrachordu hypebolaión jsou odvozeny sestupně od stupně nété hypebolaión (LL, 2304):

„Si igitur ex.II.CCCIIII. octavam abstulero partem, id est .CCLXXXVIII. eisdemque adiecero, fient mihi .II.DXCII. eritque .KK. .II.DXCII., quae est paranete hyperboleon ad neten hyperboleon obtinens distantiam tonum. " 12

„Pokud pak odeberu z 2304 [LL, nete hyperboleon] osmou část, což je 288 [2304/8], a přidám ji $k$ 2304, dostanu tak 2592, což bude [stupeň] KK 2592, paranété hypebolaión [diatonon], který se nacházi ve vzdálenosti jednoho tónu od nété hypebolaión. "

Touto jednoduchou aritmetickou metodou je odvozen i další stupeň trité hypebolaión diatonon (který právě v předchozím geometrickém dělení chybí) od stupně paranété hypebolaión diatonon:

ecclesiastici de musica sacra potissimum, 3 sv., Gerbert, Martin (ed.), St. Blaise: Typis San-Blasianis, 1784, 2:230-265).

11 GODOFREDUS Friedlein (ed.). Anicii Manlii Torquati Severini Boetii..., op. cit., kniha čtvrtá, s. 318-319. 
„Rursus eius, quae est .KK. id est .II.DXCII. aufero octavam, quae est .CCCXXIIII. eamque eis, quorum est octava, subiungo eruntque.II.DCCCCXVI. fietque mihi .FF. trite hyperboleon diatonos in diatonico scilicet genere. II. DCCCCXVI., tonum quidem distans ab ea, quae est paranete hyperboleon diatonos, ditonum vero ab ea, quae est nete hyperboleon. "13

„A opět z onoho, co je KK, tedy 2592, vyjmu jednu osminu [aufero octavam], což je 324, prípojím ji pod [subiungo erutque, tj. na levou stranu monochordu směrem k nižším tónům] KK 2592 [tj. eamque eis, quorum est octava] a dostanu 2916. Tím dostanu FF trité hypebolaión diatonon 2916, přirozeně v diatonickém rodu [genere], vzdálený jeden tón od paranété hypebolaión diatonon a dva tóny [ditonum, velká tercie] od nété hypebolaión. “

Oba právě odvozené stupně, paranété hypebolaión diatonon a trité hypebolaión diatonon jsou ve vzdálenosti vždy jeden celý tón o proporci 9:8 pod předchozím, vyšším stupněm řeckého systema. Zbylý interval mezi stupni trité hypebolaión diatonon a nété diezeugmenón vyplňuje prostor ohraničený pevnými stupni tetrachordu:

„Quoniam vero si a sesquitertia proportione duas sesquioctavas abstulero, relinquetur mihi semitonium minus, sumo tertiam eius, quae est .LL., id est nete hyperboleon; sunt .DCCLXVIII. Hos eisdem adicio, fient mihi .III.LXXII., quorum est .DD. nete diezeugmenon continens ad triten hyperboleon semitonium minus. " 14

„Jelikož pokud od proporce sesquitertia vyjmu dvě proporce sesquioctava, zůstane mi malý pưltón, vezmu jednu třetinu z LL, což je nété hypebolaión, dostanu 768. Připočitám ji k LL nété hypebolaión a dostanu 3072, což je DD nété diezeugmenón, který společněs strité hypebolaión ohraničuje malý půltón. “

Tím se završuje aritmetická definice diatonického tetrachordu hepebolaión, kterou pro přehlednost definujeme ve tvaru složené proporce:

$2304: 2592: 2916: 3072$

nété hypebolaión : paranété hypebolaión : trité hypebolaión : nété diezeugmenón

Intervalové proporce tetrachordu: 9:8 - 9:8 - 256:243 (tonus - tonus - semitonium).

Zůstává aritmeticky odvodit chromatický a enharmonický rod. Stupně nété hypebolaión a nété diezeugmenón zůstávají (jako „pevné“ stupně) v chromatice i enharmonice nezměněné; diatonický stupeň trité hypebolaión je aritmeticky, a tedy i proporčně totožný se chromatickým trité hypebolaión a enharmonickým paranété hypebolaión. Boëthius tedy nejdřive definuje chromatický stupeň paranété hypebolaión:

„Quoniam enim paranete hyperboleon ad neten hyperboleon in diatonico quidem genere tono distat, in chromatico vero tribus semitoniis, in enarmonio vero duobus tonis, si distantiam paranetes hyperboleon et netes hyperboleon diatonici

$\begin{array}{ll}13 & \text { Ibid., s. } 319-320 . \\ 14 & \text { Ibid., s. } 320 .\end{array}$ 
generis sumpserimus eiusque dimidium paranete hyperboleon, quae est diatonici generis, apponamus, habebimus numerum tribus semitoniis ab hyperboleon nete distantem; et erit haec in chromatico genere paranete hyperboleon. Aufero igitur de.II.DXCII., id est paranete hyperboleon diatonici generis, .II.CCCIIII., id est neten hyperboleon, relinquuntur mihi .CCLXXXVIII. Hos divido, erunt .CXLIIII. Eosdem .II.DXCII. adiungo, fient.II.DCCXXXVI. .HH. Haec erit paranete hyperboleon chromatica. "15

„Jelikož paranété hypebolaión je od nété hypebolaión v diatonickém rodu vzdálen o jeden tón, nicméně $v$ chromatickém o tři půltóny a v enharmonickém o dva tóny, pokud vezmeme polovinu této vzdálenosti mezi paranété hypebolaión a nété hypebolaión diatonických rodů a pridáme ji k paranété hypebolaión, který je diatonického rodu, dostaneme čislo stojíci ve vzdálenosti tři půltónu od nété hypebolaión; a to bude pak v chromatickém rodu paranété hypebolaión. Tedy pokud odčitám od 2592, tj. paranété hypebolaión diatonického rodu, 2304, tj. nété hypebolaión, dostanu zbylých 288. Tyto rozdělím [na dvě části], co bude 144 a pridám je ke 2592, dostanu 2736, HH. Toto bude paranété hypebolaión chromatického rodu."

Výsledná složená proporce chromatického tetrachordu hypebolaión bude tedy následující:

$2304: 2736: 2916: 3072$

nété hypebolaión : paranété hypebolaión : trité hypebolaión : nété diezeugmenón

Intervalové proporce tetrachordu: 19:16 - 81:76 - 256:243 (tribus semitoniis - semitonium - semitonium).

Za zmínku stojí nepravidelnost půltónů chromatického tetrachordu hypebolaión. Poslední stupeň, který je potřebné odvodit a ustavit tak enharmonický tetrachord hypebolaión, je chromatický trité hypebolaión:

„Rursus quoniam trite hyperboleon vel diatonica vel chromatica duos tonos distat a nete hyperboleon et in enarmonio genere paranete hyperboleon duobus tonis distat ab ea, quae est nete hyperboleon, eadem erit in enarmonio genere paranete hyperboleon, quae est in diatonico vel chromatico trite hyperboleon. Sed quoniam trite hyperboleon diatonici generis et chromatici ad neten diezeugmenon minus semitonium servant, constat autem tetrachordum enarmonii generis ex duobus integris tonis et diesi ac diesi, quae sunt dimidia spatia semitonii minoris, distantiam eam, quae est inter neten diezeugmenon et paraneten hyperboleon enarmonion sumo. Sed quoniam nete diezeugmenon est.III.LXXII. paranete autem hyperboleon enarmonios .II.DCCCCXVI. horum distantia erit .CLVI. Horum sumo dimidiam partem, qui sunt.LXXVIII. Hos adicio .II.DCCCCXVI., fient .II. DCCCCXCIIII. Haec erit .EE. trite hyperboleon enarmonios. " ${ }^{16}$

„,Vzhledem $\mathrm{k}$ tomu, že trité hypebolaión jak diatonického, tak chromatického rodu jsou od nété hypebolaión vzdálené o dva tóny [ditonus] a v enharmonickém 
rodu je paranété hypebolaión od nété hypebolaión vzdálený o dva tóny, to, co bude v enharmonickém paranété hypebolaión, bude v diatonickém a chromatickém rodu trité hypebolaión. Jelikož od trité hypebolaión diatonického a chromatického rodu zbývá do nété diezeugmenón malý půltón, na druhou stranu tetrachord enharmonického rodu pozůstává z dvou celých tónů a $z$ diesis a diesis, které jsou rozdělením prostoru malého půltónu, jeho vzdálenosti, kterou vezmu mezi nété diezeugmenón a paranété hypebolaión - ale enharmonického rodu. Protože nété diezeugmenón je 3072 a paranété hypebolaión enharmonického rodu 2916, jejich vzdálenost bude 156. Vezmu půlku této části, která je 78, a pridám ji $k 2916$ a dostanu 2994. Toto bude EE trité hypebolaión enharmonického rodu. “

Složená proporce enharmonického tetrachordu hypebolaión bude následující:

$2304: 2916: 2994: 3072$

nété hypebolaión : paranété hypebolaión : trité hypebolaión : nété diezeugmenón

Intervalové proporce tetrachordu: 81:64 - 499:486 - 512:499 (ditonus - diesis - diesis).

Podobným aritmetickým dělením Boëthius odvozuje i zbylé tetrachordy řeckého systema: tetrachord diezeugmenón, synémmenón, mesón a nakonec hypatón. Jejich složené i intervalové proporce rekonstruujeme dle původního textu ${ }^{17}$, intervalové schéma je identické s tetrachordem hyperbolaión, proto jej již neopakujeme.

Složené proporce tetrachordů diezeugmenón (nété diezeugmenón : paranété diezeugmenón : trité diezeugmenón : paramesé):

diatonický: $\quad 3072: 3456: 3888: 4096$

chromatický: $\quad 3072: 3648: 3888: 4096$

enharmonický: $3072: 3888: 3992: 4096$

Složené proporce tetrachordů synémmenón (nété synémmenón : paranété synémmenón : trité synémmenón: mesé):

diatonický: $\quad 3456: 3888: 4374: 4608$

chromatický: $3456: 4104: 4374: 4608$

enharmonický: $3456: 4374: 4491: 4608$

Složené proporce tetrachordů mesón (mesé : lichanos mesón : parhypaté mesón: hypaté mesón):

diatonický: $\quad 4608: 5184: 5832: 6144$

chromatický: $\quad 4608: 5472: 5832: 6144$

enharmonický: $4608: 5832: 5988: 6144$

Složené proporce tetrachordi̊ hypatón (hypaté mesón : lichanos hypaté : parhypaté hypatón: hypaté hypatón):

diatonický: $\quad 6144: 6912: 7776: 8192$

chromatický: $\quad 6144: 7296: 7776: 8192$

enharmonický: 6144 : 7776: 7984 : 8192

17 Ibid., s. 324-334. 
Všechna čísla představující délku monochordu jednotlivých stupňů všech tetrachordů a rodů můžeme na závěr př́íspěvku sestavit do úplné složené proporce celého systému. Pro názornost jsou názvy neměnných stupňů (tj. stupňủ společných všem rodům) zvýrazněné tučným fontem, diatonické stupně normálním fontem, chromatické kurzívou a enharmonické podtržením:

2304 nété hypebolaión

2592 paranété hypebolaión

2736 paranété hypebolaión

2916 trité hypebolaión = trité hypebolaión $=$ paranété hypebolaión

2994 trité hypebolaión

3072 nété diezeugmenón

3456 paranété diezeugmenón = nété synémmenón

3648 paranété diezeugmenón

3888 trité diezeugmenón $=$ trité diezeugmenón $=$ paranété diezeugmenón $=$ paranété synémmenón

3992 trité diezeugmenón

4096 paramesé

4104 paranété synémmenón

4374 trité synémmenón $=$ trité synémmenón $=$ paranété synémmenón

4491 trité synémmenón

4608 mesé

5184 lichanos mesón

5472 lichanos mesón

5832 parhypaté mesón $=$ parhypaté mesón $=\underline{\text { lichanos mesón }}$

5988 parhypaté mesón

6144 hypaté mesón

6912 lychanos hypatón

7296 lychanos hypatón

7776 parhypaté hypatón = parhypaté hypatón $=$ lychanos hypatón

7984 parhypaté hypatón

8192 hypaté hypatón

9216 proslambanomenos

Odvození diatonického rodu je v Boëthiově De institutione musica realizováno metodou geometrického dělení $\mathrm{v}$ rámci řeckého tónového systému jako celku. Tato metoda je později tradována ve středověku, i když nikoli v kontextu systema teleion, nýbrž v kontextu systému hexachordů. Pro geometrické dělení je př́značná praktická možnost dělení přímo na struně monochordu. Naproti tomu aritmetické argumentace, jimiž odvozuje Boëthius kromě diatonického rodu i chromatický a enharmonický, již tuto př́mou souvislost s praktickým využitím postrádají, ačkoli i aritmetické dělení lze přeformulovat pro nanesení na monochord. Tyto souvislosti jsou důležité z hlediska porozumění vztahům mezi spekulativními aritmetickými koncepcemi (přisuzovanými pythagorejské tradici) a empirickými aspekty uvažování o hudbě. 
Martin Celhoffer (celhoffer@phil.muni.cz) vystudoval hudební vědu na FF MU v Brně. V současnosti působí jako odborný asistent na Akademii staré hudby při ÚHV FF MU. Pedagogicky působí také na KTDU FU Ostravské univerzity. Badatelsky se zaměřuje na hudebně-teoretickou problematiku a filozofii umění.

\section{ABSTRACT \\ SYSTEMA IN DE INSTITUTIONE MUSICA - CONNECTION OF ARITHMETIC, GEOMETRY AND MUSIC}

This study deals with the methods of derivation of the Greek Systema Teleion in Boethius' influential treatise De Institutione Musica. Boethius applied two basic methods of division: geometrical and arithmetical. The geometrical one is related to diatonic division of a string of the monochord, the arithmetical one is related to detailed description of tetrachord species.

\section{Key words}

tetrachord, systema teleion, De institutione musica, Greek genera, quadrivium

\section{Bibliography}

BOETHIUS, Anicius Manlius Severinus. Fundamentals of Music. Překl. Calvin M. Bower. Ed. Claude V. Palisca. New Haven \& London: Yale University Press, 1989.

CELHOFFER, Martin. „Sectio canonis. Geometrická konstrukce hudebních intervalů řeckého systema teleion". Opus musicum, 2012, roč. 44, č. 2, s. 59-67.

ČERNÝ, Miroslav K. Hudba antických kultur. Praha: Academia, 2006.

GODOFREDUS, Friedlein (ed.): Anicii Manlii Torquati Severini Boetii De institutione arithmetica libri duo: De institutione musica libri quinque. Accedit geometria quae fertur Boetiis. Lipsko: B.G.Teubner, 1867.

GUIDO z Arezza. Epistola de ignoto cantu directa. In Scriptores ecclesiastici de musica sacra potissimum, 3 sv. Martin Gerbert (ed.). St. Blaise: Typis San-Blasianis, 1784, 2:43-50.

GUIDO z Arezza. Micrologus. In Scriptores ecclesiastici de musica sacra potissimum, 3 sv. Martin Gerbert (ed.). St. Blaise: Typis San-Blasianis, 1784, 2:2-24.

COTTO, Johannes de. Musica (Ex MS. San-Blas. saec. XII. collato cum Vindobonensi \& Lipsiensi. In Scriptores ecclesiastici de musica sacra potissimum, 3 sv. Gerbert, Martin (ed.). St. Blaise: Typis San-Blasianis, 1784, 2:230-265.

MATHIESEN, Thomas J. „An Annotated Translation of Euclid's Division of a Monochord“. Journal of Music Theory, 1975, roč. 19, č. 2, s. 249-252. 